\title{
A case of bilateral self-induced keratoconus in a patient with tourette syndrome associated with compulsive eye rubbing: case report
}

\author{
Artemios Kandarakis ${ }^{1}$, Michael Karampelas ${ }^{2 *}$, Vasileios Soumplis ${ }^{1}$, Christos Panos $^{1}$, Nikolaos Makris ${ }^{1}$, \\ Stylianos Kandarakis ${ }^{3}$ and Dimitrios Karagiannis ${ }^{1}$
}

\begin{abstract}
Background: Tourette syndrome is a neurologic disorder that is characterized by repetitive muscle contractions that produce stereotyped movements or sounds. Approximately 50\% of individuals with TS also exhibit obsessivecompulsive behaviors including eye rubbing. We report a case of bilateral self-induced keratoconus in a patient with TS, associated with compulsive eye rubbing.
\end{abstract}

Case presentation: A 35-year-old man was first seen in our clinic as an outpatient due to rapid deterioration of vision in his right eye associated with pain and tearing, over a period of one month. Slit lamp biomicroscopy of the right eye showed a central stromal scar due to corneal hydrops. Clinical examination and corneal topography of the left eye were normal. Six months later the patient developed corneal hydrops of his left eye. During the following examinations his vision continued to deteriorate in both eyes, while a central stromal scar was forming in his left cornea. Four years after the initial examination the patient's visual acuity was no light perception in the right eye and counting fingers at $33 \mathrm{~cm}$ in the left eye. His right eye was phthisic.

Conclusions: Our patient developed a rapidly progressing bilateral corneal ectasia and phthisis of his right eye during a time period of 4 years. This unusual pattern suggests that the patient's compulsive behavior compromised both of his corneas and led to bilateral keratoconus.

\section{Background}

Tourette syndrome (TS) was first described in 1885 by French physician Gilles de la Tourette. TS is a neurologic disorder that is characterized by repetitive muscle contractions that produce stereotyped movements (motor tics) or sounds (vocal tics). Approximately 50\% of individuals with TS also exhibit obsessive-compulsive behaviors [1]. Eye tics (blinking, alterations in gaze, rubbing of the eyes, blepharospasm, etc.) are well known as early manifestations of TS [2], while there are reports which associate this syndrome with color vision deficiencies [3], self-induced bilateral retinal detachment [4] and visual field defects [5]. We report a case of bilateral self-induced keratoconus in a patient with TS, associated with compulsive eye rubbing. To the best of our

\footnotetext{
* Correspondence: michael.karampelas@moorfields.nhs.uk

${ }^{2}$ Moorfields Eye Hospital, 162 City Road,London, EC1V 2PD, UK

Full list of author information is available at the end of the article
}

knowledge this is the first longitudinal report of corneal ectasia associated with TS, describing the progression of keratoconus during a follow-up period of four years. This case report follows all the guidelines required by the Ethics Committee of which all authors are affiliated.

\section{Case Presentation}

A 35-year-old man (K.E) was first seen in our clinic as an outpatient due to a rapid deterioration of vision in his right eye associated with pain and tearing, over a period of one month. He also noted a gradual decline of vision in his right eye over the previous year. His medical history included TS diagnosis since childhood, asthma, mild depression and low grade myopia in both eyes from the age of 7 . He was on aripiprazol, clonazepam and sertraline. During the examination the patient did not have extensive vocal tics but he manifested several motor tics including frequent bilateral eye rubbing. The patient did not have any symptoms of ocular
C Biomed Central

(ㄷ) 2011 Kandarakis et al; licensee BioMed Central Ltd. This is an Open Access article distributed under the terms of the Creative Commons Attribution License (http://creativecommons.org/licenses/by/2.0), which permits unrestricted use, distribution, and reproduction in any medium, provided the original work is properly cited. 
itching or irritation and on questioning he reported vigorous rubbing in both eyes.

At baseline examination, best corrected visual acuity (BCVA) was counting fingers at $0,5 \mathrm{~m}$ in the right eye and $9 / 10$ in the left eye (with $-2,50 \mathrm{sph},-1,50 \mathrm{cyl} \times 90$ correction). Slit lamp biomicroscopy of the right eye showed a central stromal scar secondary to corneal hydrops (Figure 1a), while his left eye was normal. There was no evidence of papillary or follicular lesions on both tarsal conjunctivae. His intraocular pressures were normal. Corneal topography of his left eye was normal (Figure 2a).

Axial lengths as measured by immersion A-scan ultrasonography were $25,14 \mathrm{~mm}$ in the right eye and 24,71 $\mathrm{mm}$ in the left eye, while B-scan ultrasonography did not show any pathologic findings.

We treated the right eye with hypertonic saline drops, cycloplegic drops and advised the patient to avoid eye rubbing.
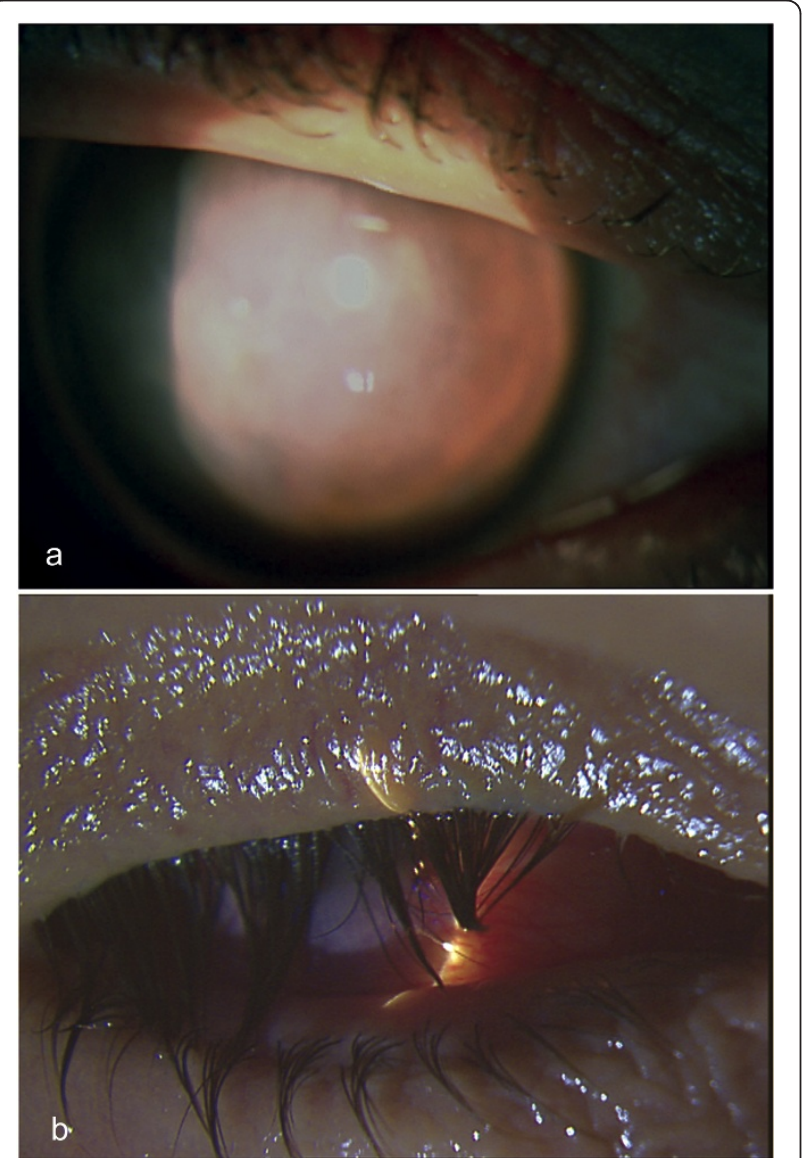

Figure 1 Biomicroscopic appearance of the right eye at presentation showing central stromal scar (a) and 4 years after presentation showing phthisis (b). Short title: Biomicroscopic appearance of the right eye at presentation and 4 years later.
Six months later, the patient presented complaining of sudden drop in vision in his left eye. BCVA was counting fingers at $33 \mathrm{~cm}$ in his right eye and had declined to $1 / 10$ in the left eye. Slit lamp biomicroscopy showed corneal hydrops of the left eye with accompanying epithelial loss. We treated the left eye with topical hypertonic saline drops, cycloplegic drops, oral acetazolamide, an eye shield at night and strongly advised him to avoid eye rubbing. We also contacted the patient's general practitioner which informed us that the patient did not had a close psychiatric surveillance, while he failed to appear in many of his routine appointments over the last years.

One year later BCVA was hand motion in his right eye and counting fingers at $2 \mathrm{~m}$ in his left eye with normal light projections while during the following months his vision continued to deteriorate in both eyes with central stromal scar formation in the left cornea (Figure 3 ). Corneal topographies of his left eye showed a corresponding progression (Figure $2 \mathrm{~b}$ ). Four years after presentation BCVA was no light perception in the right eye and counting fingers at $33 \mathrm{~cm}$ in the left eye. His right eye was phthisic (Figure 1b).

Keratoconus is a bilateral non-inflammatory corneal ectasia with an incidence of approximately 1 per 2000 in the general population [6]. Although its most common presentation is as an isolated sporadic disorder, it has also been associated with various diseases. An indication of a connection between keratoconus and TS is implied in a preliminary report by Enoch et al [5]. In this report which primarily investigates visual field defects in a group of 12 patients with TS, it is noted that two patients exhibited keratoconus, with no further analysis concerning the aetiologic relationship between the two conditions. Furthermore, Mashor et al recently described three cases of patients with TS-provoked eye rubbing that exhibited keratoconus [7].

There are multiple studies that report a high association of eye rubbing with keratoconus, but a cause-andeffect relationship is difficult to be established [8]. The association is implied by the high percentage of keratoconus patients with a positive history of eye rubbing. The reported prevalence ranges from $66 \%$ to $73 \%$ [9]. Rabinowitz performed a case-control study which showed that keratoconus patients do rub their eyes more often than normal controls $(80 \%$ versus $58 \%$, p < 0.001) [6]. Furthermore, keratoconus relates to a variety of conditions in which eye rubbing is a common feature like vernal atopic disease [10], Trisomy 21 [11] and Leber's tapeto-retinal degeneration [12]. Mechanical trauma has been implicated in the pathogenesis of keratoconus and the proposed mechanisms include increased apoptosis and increased oxidative damage [13]. 


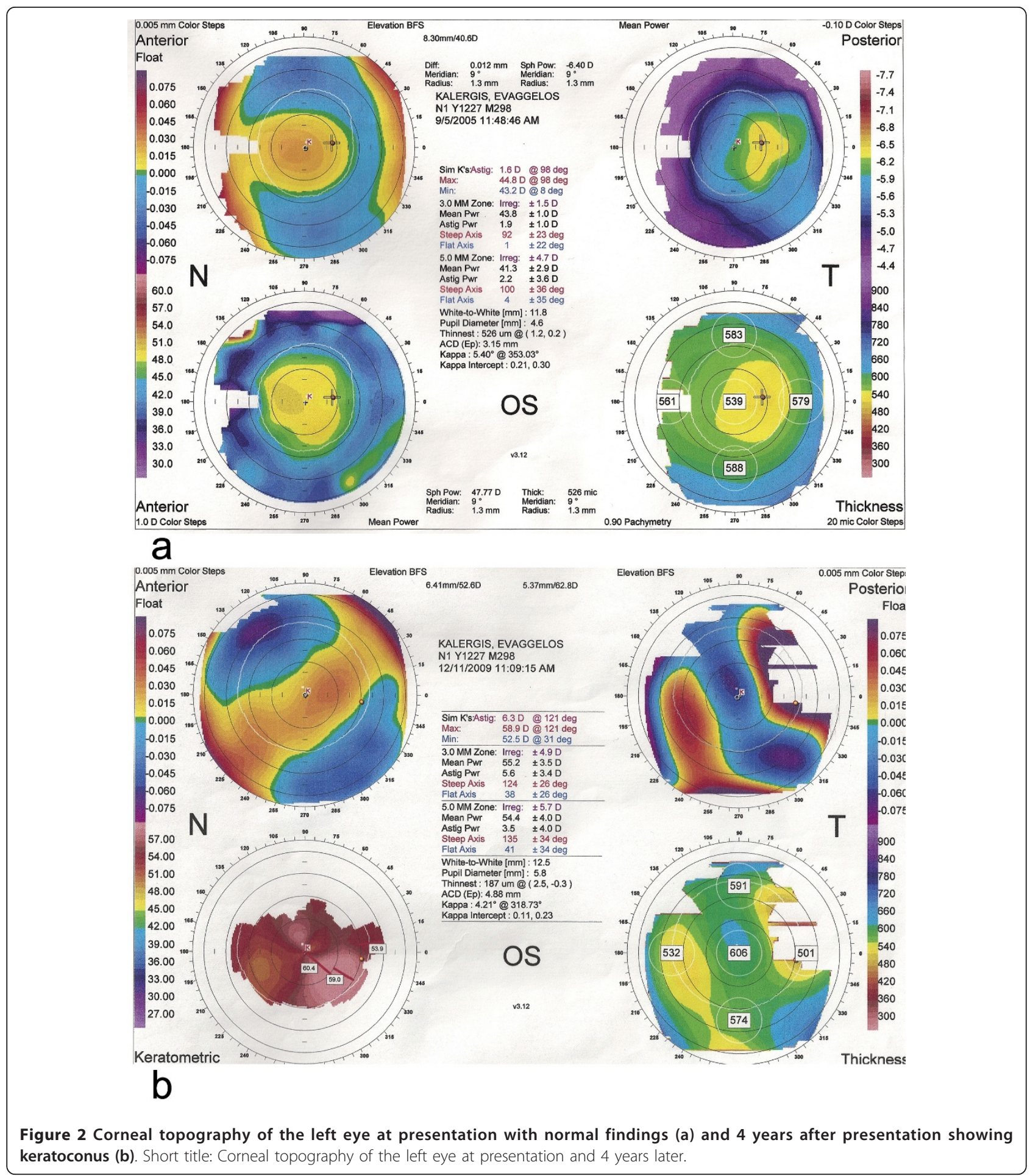

\section{Conclusions}

Our patient developed a rapidly progressing bilateral corneal ectasia and phthisis of his right eye during a time period of 4 years. It must be emphasized that although his left eye was normal at the initial examination, it developed corneal hydrops in a period of six months. This unusual pattern indicates that the patient's compulsive behavior compromised both of his corneas and led to bilateral keratoconus.

In conclusion, TS can lead to severe keratoconus associated with compulsive eye rubbing. It is therefore essential to assist patients with TS that exhibit this kind 


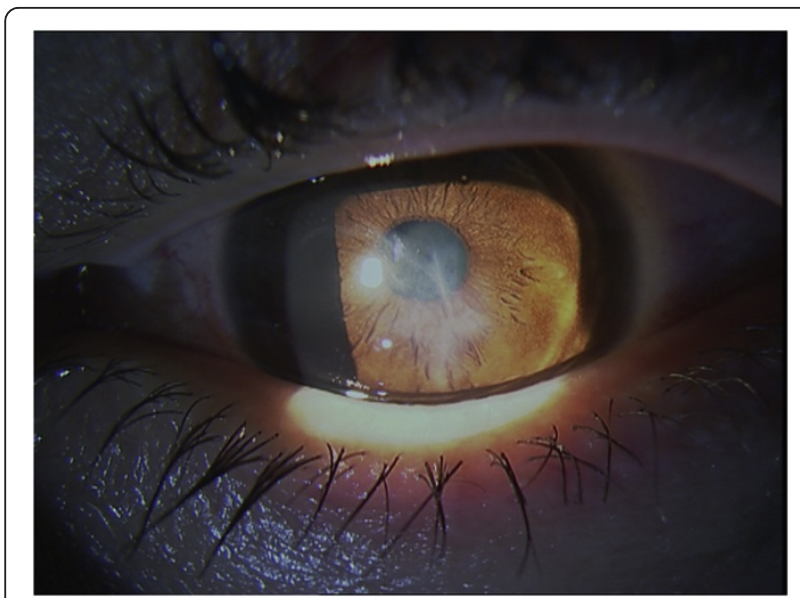

Figure 3 Biomicroscopic appearance of the left eye showing central stromal scar.

of behavior by suggesting the use of protective polycarbonate goggles and by ensuring a close surveillance in conjunction with the psychiatry service.

\section{Consent}

Written informed consent was obtained from the patient for publication of this case report and any accompanying images.

\section{Acknowledgements and Funding}

The authors do not have any acknowledgements to state.

No financial support was received.

\section{Author details}

${ }^{1} 1$ st Ophthalmology Department, Ophthalmiatrion Eye Hospital of Athens, Sina 2, Athens, 106 72, Greece. ${ }^{2}$ Moorfields Eye Hospital, 162 City Road, London ,EC1V 2PD, UK. ${ }^{3}$ Ophthalmology Department, Weill Cornell Medical College, 1305 York Avenue at E. 70th Street, New York, NY 10021, USA.

\section{Authors' contributions}

$A K, M K, V S, C P, N M, S K$ and DK treated the patient and in doing so acquired the case data; they were also involved with drafting of the manuscript. All authors read and approved the final manuscript.

\section{Competing interests}

The authors declare that they have no competing interests.

Received: 31 May 2011 Accepted: 21 September 2011

Published: 21 September 2011

\section{References}

1. American Psychiatric Association: Diagnostic and Statistical Manual of Mental Disorders American Psychiatric Association; 1994.

2. Golden G: Tourette syndrome: recent advances. Pediatr Neurol 1986, 2:189-92.

3. Melun JP, Morin LM, Muise JG, DesRosiers M: Color vision deficiencies in Gilles de la Tourette syndrome. J Neurol Sci 2001, 186(1-2):107-10.

4. Lim S, Rezai KA, Abrams GW, Eliott D: Self-induced, bilateral retinal detachment in Tourette syndrome. Arch Ophthalmol 2004, 122(6):930-1.

5. Enoch JM, Itzhaki A, Lakshminarayanan V, Comerford JP, Lieberman M: Visual field defects detected in patients with Gilles de la Tourette syndrome: preliminary report. Int Ophthalmol 1989, 13(5):331-44.

6. Rabinowitz YS: Keratoconus. Surv Ophthalmol 1998, 42(4):297-319.
7. Mashor RS, Kumar NL, Ritenour RJ, Rootman DS: Keratoconus caused by eye rubbing in patients with Tourette Syndrome. Can J Ophthalmol 2011, 46(1):83-6.

8. Krachmer JH, Feder RS, Belin MW: Keratoconus and related noninflammatory corneal thinning disorders. Surv Ophthalmol 1984, 28(4):293-322.

9. Karseras AG, Ruben M: Aetiology of keratoconus. Br J Ophthalmol 1976, 60(7):522-5.

10. Gasset AR, Hinson WA, Frias JL: Keratoconus and atopic diseases. Ann Ophthalmol 1978, 10(8):991-4.

11. Rados A: Conical cornea and mongolism. Arch Ophthal 1948, 40(4):454-78.

12. Karel I: Keratoconus in congenital diffuse tapetoretinal degeneration. Ophthalmologica 1968, 155(1):8-15.

13. McMonnies CW: Mechanisms of rubbing-related corneal trauma in keratoconus. Cornea 2009, 28(6):607-15.

Pre-publication history

The pre-publication history for this paper can be accessed here: http://www.biomedcentral.com/1471-2415/11/28/prepub

doi:10.1186/1471-2415-11-28

Cite this article as: Kandarakis et al:: A case of bilateral self-induced keratoconus in a patient with tourette syndrome associated with compulsive eye rubbing: case report. BMC Ophthalmology 2011 11:28.

\section{Submit your next manuscript to BioMed Central and take full advantage of:}

- Convenient online submission

- Thorough peer review

- No space constraints or color figure charges

- Immediate publication on acceptance

- Inclusion in PubMed, CAS, Scopus and Google Scholar

- Research which is freely available for redistribution 